\title{
AS NOIVAS VERMELHAS
}

\author{
THE RED FIANCÉE
}

\section{Resumo}

Este ensaio discute o suicídio feminino a partir das relações de gênero. Nós abordamos o suicídio feminino em duas culturas, China e Brasil. A partir das conexões deste evento nas interações culturais feminino-masculino, surgiram diferentes estratégias de desqualificação do feminino que estavam relacionadas ao suicídio, sejam estas, estratégias discursivas ou comportamentais. Assim, podemos considerar que o suicídio feminino é um evento social e intrinsicamente relacionado a questão da identidade da mulher nas duas culturas.

Palavras-chave: Suicídio. Gênero. Cultura.

\begin{abstract}
This essay discusses the female suicide from gender relations. We approach the female suicide in two cultures, China and Brazil. From the connections of this event in the male-female cultural interactions emerged different female disqualification strategies that were related to suicide, whether, discursive and behavioral strategies. So, we can consider that female suicide is a social event and intrinsically related to the issue of women's identity in the two cultures.
\end{abstract}

Keywords: Suicide. Gender. Culture.

\section{Introdução}

O que instigou este ensaio foi um comentário fortuito durante um percurso no trânsito da metrópole de São Paulo. Ao passar pela Avenida Prestes Maia, embaixo do viaduto Passarela Rua das Noivas, eu comentei com meu interlocutor: Você sabia que muitas noivas se suicidam neste viaduto quando seus casamentos são rompidos? ${ }^{\text {. }}$ Ele, um homem chinês, me respondeu: Na China, também, as noivas abandonadas se suicidam com seus vestidos vermelhos de casamento ${ }^{2}$. Elas são o pior tipo de fantasma que existe para um homem, pois perseguem o noivo por toda vida!

Naquele momento, visualizei a cena da noiva suicida, vestida de vermelho e, depois, por dias, estive imaginando seu fantasma seguindo seu noivo para sempre. As cenas suicidas são muito significativas para compreender o ato de suicídio desde que fiz minha pesquisa inicial sobre o tema.

\footnotetext{
1 A "Passarela das Noivas" está situada na região central da cidade de São Paulo, sendo esta área conhecida pelo seu comércio de vestidos de noivas e outros artefatos do gênero. Ao transitar pela região ou sob a passarela, é possível observar suas inúmeras lojas com vestidos de noiva nas vitrines. A informação sobre o suicídio das noivas eu obtive durante trabalho de campo anterior sobre o tema naquela área.
}

2 Na China é uma tradição a noiva usar vestido vermelho, a cor significa sorte.

Fernanda Cristina Marquetti

Universidade Federal de São Paulo (UNIFESP). E-mail: femarquetti@uol.com.br 
A cena construída pelo suicida nunca é aleatória, ela traz várias informações sobre o evento e está impregnada pelas questões socioculturais do sujeito. $\mathrm{O}$ ambiente do sujeito fornece $\mathrm{o}$ material disponível para que a cena seja construída, ele recolhe o que considera mais significativo para seu ato e reelabora estes objetos dando-lhes novos significados. A cena suicida, apoiada no seu cenário, traz elementos intrigantes que podem revelar particularidades do sujeito, que aparentemente eram estranhamentos, manias, desvio patológico. Porém, a análise dessas peculiaridades pode nos mostrar outras dimensões do sujeito e sua relação com o meio sociocultural e, assim, retirar o suicídio de um enquadre de anormalidade para uma vertente que aponta para a interação sujeito-cidade. O suicídio, sob esta ótica, deixa de ser algo incompreensível, anormal para mostrar uma articulação extremada de conflito que não encontra outra resolução exceto a morte. (Marquetti, 2013: 26-27).

A perspectiva de um imaginário oriental, masculino, sobre a malignidade dessas mulheres, mesmo depois de mortas, também permaneceu como uma miragem. Qual seria a força desses fantasmas femininos e por quê?

Estes elementos iniciais me arrastaram para um processo de busca do evento descrito e compreensão deste imaginário tão intenso e supersticioso sobre os suicídios dessas mulheres chinesas. E, reverberando neste pensamento, ajuizei sobre aquilo que era ordinário entre estas mulheres: aquelas que se suicidam na passarela das noivas em São Paulo e as chinesas suicidas com seus vestidos vermelhos. Embora, separadas pela discrepância das culturas, ocidente e oriente, elas mantinham algo em comum: a condição de noivas abandonadas. Assim, o feminino e sua composição com o masculino, por vezes trágicas, tomou seu lugar neste ensaio. Desta forma, embora nosso foco principal seja o suicídio feminino, resvalamos numa questão de gênero. Desde já, esclarecemos que adotamos uma perspectiva relacional da questão de gênero nesta discussão sobre suicídios femininos, pois foi na relação entre os gêneros que encontramos os vieses do evento suicida e suas consequências para ambos. Sobre esta perspectiva de estudo de gênero, citamos:

A análise sobre essa tradição nos remete, assim, à necessidade de reflexões sobrea construção de masculinidades efeminilidades que vão além da vitimização de alguns (mulheres) e da culpabilização de outros (homens). Afinal, reconhecer a dimensão relacional do gênero possibilita desconstruir principalmente os argumentos culpabilizantes sobre os homens que demarcam o discurso de parte do movimento feminista e que ainda se faz presente, direta ou indiretamente, nas produções acadêmicas contemporâneas. (Medrado \& Lyra, 2008: 9) 


\section{A Busca de um Percurso para Reflexão}

Apesar das pesquisas para obter informações sobre essas noivas suicidas chinesas e a superstição que as acompanha, nada encontrei sobre o assunto; assim, temos apenas a memória oral desses eventos relatada no início. Por outra via, ao buscar sobre a vida das mulheres chinesas, sua cultura, seu cotidiano, a perspectiva sobre o masculino-feminino na China, me deparei com inúmeros relatos de suicídios femininos, seja em livros, artigos ou teses. Observamos que o tema central destes textos, provenientes da literatura, do jornalismo, entre outras áreas das humanidades, não versava sobre suicídio e sim sobre as mulheres chinesas. O suicídio se mostrou intrinsicamente relacionado à vida das mulheres na China.

Uma lembrança submersa na minha memória emergiu, os dados epidemiológicos apontam, de forma desafiadora, que a China é um dos únicos países onde as taxas de óbito por suicídio são maiores entre mulheres. Citamos:

A China é um dos únicos países que apresenta mortalidade feminina por autoagressão maior que a masculina e, neste país, os casos ocorrem predominantemente entre mulheres jovens, rurais, pobres, com baixa escolaridade, poucas oportunidades de trabalho e em situação de submissão a maridos ou família. (Ying, et al, 2014.).

Mello-Santos et al (2005) aponta que as taxas de mortalidade por suicídio são de 3 a 4 vezes maiores em homens na maioria dos países do mundo. Meneghel et al (2013) observa que nos países asiáticos a taxa de suicídio é similar entre os sexos e os únicos países do mundo que apresentam uma taxa de mortalidade maior entre as mulheres são a China e a Índia. Diante destes dados específicos, a autora aponta para vertentes socioculturais, ou seja, questiona a perspectiva de que o suicídio estaria relacionado a fatores biológicos ligados ao sexo.

Entretanto, as considerações teóricas que explicariam tal desproporção na taxa de óbitos por suicídio feminino entre a China e os países restantes, permanece pouco explorada. Muitas vezes encontramos o comentário nebuloso para explicar os suicídios consumados entre as chinesas: questões culturais.

$\mathrm{O}$ que seriam estas questões culturais que promovem tamanha diferença entre os diversos países e a China no tocante aos suicídios femininos?

Acredito que possibilidades de reflexão sobre uma demanda admitem duas perspectivas: o conteúdo e a forma. Neste caso, o conteúdo sempre termina na resposta enigmática: questões culturais. Então, podemos nos lançar sobre a forma, no objetivo de alcançar uma compreensão do conteúdo.

Se pudéssemos traçar um(a) desenho/forma desta demanda, teríamos como ponto nevrálgico, suicídios femininos singulares e emblemáticos, ou seja, as noivas suicidas. Também, temos um fio condutor imaginário que associa mulheres 
de diferentes continentes em eventos suicidas. E, finalmente, temos como pano de fundo o script destes eventos suicidas: no primeiro, a cena de uma mulher abandonada com seu vestido de noiva vermelho, que comete suicídio. A ênfase desta cena aponta para o vestuário e sua força simbólico/trágica, pois o vestido vermelho, que significa sorte na China, se transforma em azar. No segundo script temos cenas de mulheres abandonadas pelos noivos que se atiram da Passarela Rua das Noivas. Nesta cena, a ênfase recai sobre o cenário. Aquela passarela que poderia simbolizar a passagem entre a condição de solteira/noiva para casada, em uma possível referência ao percurso no átrio da igreja, transforma-se na passagem da vida para a morte. Ambos os scripts estão permeados pelos elementos: masculino-feminino e a suposta junção destes, nestes casos, tragicamente não concretizados. Assim sendo, guiada pela perspectiva da forma desta demanda, proponho uma discussão sobre o lugar simbólico da mulher e suas possíveis relações com o suicídio.

\section{O Suicídio Feminino na China}

"Numa mulher, a falta de talento é uma virtude". (Aforisma atribuído a Confúcio.)

A tradicional cultura chinesa preserva valores milenares que estão incrustrados na forma de agir e pensar da sociedade contemporânea. Seus valores tradicionais perpassaram séculos de história, de guerras e da Revolução Cultural de Mao Tsé Tung. ${ }^{3}$ Dentre estes valores, está o lugar ocupado pela mulher na cultura chinesa. Esta tradição é o pano de fundo no qual podemos observar as relações masculinofeminino sendo construídas na sociedade atual. Desta forma, conhecer os princípios culturais, filosóficos e religiosos colabora para a compreensãsimbólico da mulher, ou, a falta dele. A epígrafe de Confúcio, filósofo que marcou profundamente o pensamento oriental-chinês, revela que a ausência é a característica desejada para o feminino. Vejamos, também, as colocações sobre estudos culturais da China:

A primeira personalidade que marca a história chinesa no seu código de conduta moral é o Imperador Shun. Os valores éticos que instituiu ao povo chinês estão relacionados essencialmente com a família, valores esses que ainda vigoram atualmente. $\mathrm{Na}$ ideologia do Taoísmo existem os símbolos de Yin e Yang. Yin significa o princípio da mulher e Yang o do homem. Podemos ver que no símbolo são simétricos-têm direitos iguais-mas na cultura tradicional a família vem primeiro do que o indivíduo, os homens são mais valorizados do que as mulheres e existe o respeito pelos mais velhos. A questão da desigualdade de género

3 Mao Tsé-Tung foi um político, teórico, líder comunista e revolucionário chinês. Liderou a Revolução Chinesa e foi o arquiteto e fundador da República Popular da China, governando o país desde a sua criação em 1949 até sua morte. Sendo atribuído a ele os primeiros movimentos de reconhecimento social e dos direitos da mulher chinesa. 
perdura na China, mas já foram feitos alguns avanços para a igualdade. Contudo, ainda existem muitos traços confucionistas que persistem na atualidade. De facto, o confucionismo foi a religião oficial da China por dois mil anos e é impossível apagar em dois ou três séculos uma influência que se integrou na sociedade e na identidade de um país por tanto tempo. (Jandt, 2007: 246).

A tenacidade dos valores tradicionais da cultura chinesa, que permanecem como fonte de orientação de vida, cunhou para as mulheres, um lugar onde paira uma sombra determinada pelos ensinamentos do confucionismo. Esta penumbra sobre o feminino determina um lugar obscurecido pela imagem do outro-masculino. Apesar dos limites da nossa perspectiva ocidental para compreender uma cultura milenar e fundada em princípios filosóficos e religiosos tão diversos, podemos observar através das pesquisas que estudam o lugar da mulher na China, que até os dias de hoje prevalece um vazio de sentido próprio ao feminino. A mulher é sempre definida a partir do eixo masculino; ela e seus atributos são referenciados em função do outro. Portanto, um esvaziamento de sua identidade se processa continuamente.

A mulher chinesa tem por tradição um lugar apagado na sociedade chinesa. Ela é o elemento Yin, escuro, noctívago, recolhido. O seu brilho lunar, a exercer-se, deve ser discreto e confinar-se aos aposentos interiores da casa. Ela é dominada por um poder patriarcal que abarca todas as esferas do seu mundo. Obedece a um poder político masculino, submete-se a um poder familiar da linha do marido, verga-se a um poder religioso também ele dominado por figuras burocráticas e masculinas que decalcam a organização política e social mundana. [...] À mulher, por costume, está-lhe vedada a educação, que lhe permitiria participar ativamente na sociedade que a rodeia. Ou melhor, são-lhe fornecidos os instrumentos mínimos para que possa compreender os clássicos, feitos à sua medida e, também, para que possa enfeitar, sentimental e artisticamente, a sociedade em que está inserida. Ela é, antes de mais, um objeto de adorno, por isso, se pertencer à nobreza, sabe música, caligrafia e poesia. (Alves, 2002: 1015-1016).

Um objeto de adorno sempre é um ornamento de algo ou de alguém; neste caso do masculino e de seus territórios. Objeto secundário e com rubrica de adereço, jamais peça principal, por mais significativa que seja. O que significa para uma mulher ser ornamento? Que consequências tem para alguém existir para ornar o outro? 


\section{Os tipos femininos desejados e indesejados na cultura chinesa}

Alves (2002), também, elenca os tipos de mulheres desenhados como o ideal pela cultura chinesa através da literatura. Todos são referenciados ao masculino, ou seja, a mulher decorre do outro. A autora faz uma retrospecção do feminino nos mitos da cultura chinesa, nas figuras femininas do passado e suas consequências na mulher chinesa da sociedade contemporânea. Segundo a autora, os tipos femininos descritos na mitologia atravessam toda a China clássica e continuam vivos na memória contemporânea chinesa. Fazemos um breve resumo destes desenhos femininos na China para contextualizar a questão.

Tipos mitológicos femininos:

- A mãe modelar à maneira de $\mathrm{Nu}$ Gua, a deusa criadora, meio serpente meio humana, sendo esta uma variante da criadora e dona de casa exemplar, a esposa-amante, em Nujiao, mulher do lendário imperador Yu.

- A trabalhadora modelo, temos como exemplo, a Tecedeira, filha do imperador celestial. Ela trabalha, noite e dia, para bordar as vestes de toda a corte do seu pai.

- A concubina, que é a mulher objeto, a bela. Os deuses também casam e vivem em sistema de concubinagem em harmonia.

Tipos mitológicos femininos a serem evitados:

- A mulher desobediente, nos mitos da deusa da Lua. Este tipo traduz o que os chineses julgam ser a essência feminina, que é o tipo da mulher rebelde e que necessita ser castigada pelo seu comportamento negativo.

-A estranha, sendo personificada por deusas efiguras míticas incomuns, que possuem fisionomia diferente - habitualmente são estrangeiras. Elas revelam comportamentos dúbios ou incompreensíveis. Ela é feminina e masculina. Outras estranhas são uma espécie de amazonas; mulheres guerreiras que se mascaram de homens para poder agir num universo masculino.

\section{Figuras femininas do passado e seu reflexo na contemporaneidade chinesa}

Observamos que nos tipos femininos descritos anteriormente por Alves (2002), os eventos suicidas estavam sempre presentes, sem exceção. E, também, estes tipos mitológicos femininos perpetuam sua força no imaginário do significado da mulher na China. Neste mesmo texto é abordado o lugar da mulher nesta sociedade na atual. Vejamos as descrições: 
Mulheres da casa:

As mulheres de casa são figuras do passado, por excelência. Elas são as esposas, ou primeiras mulheres, as matriarcas, as avós poderosas, as verdadeiras mães de família, pilares de muita força, capazes de sustentar numerosas proles. São, também, certas meninas compradas em pequenas para futuros casamentos, são as mulheres de pés atados, as flores de lótus, as viúvas-noivas e as viúvas suicidas. Não são belas, não são fatais, têm normalmente fortes qualidades morais e, quase sempre, aparecem descritas como figuras altamente abnegadas [...]. As esposas entram nas casas dos maridos, onde, porlongo tempo, permanecem ofuscadas, tanto pelos maridos, como, sobretudo, pelas mães destes. As matriarcas, umas vezes, são descritas como seres que exercitam o seu poder, com verdadeiros requintes de malvadez, mas outras, são retratadas como mulheres de uma força admirável, avós que são o verdadeiro coração da família [...]. A mulher de casa é, no passado, a figura suicida por excelência. Ela é a filha devotada e dilacerada entre o amor e obediência filiais, que a obrigam a uma submissão cega aos desejos paternos e o seu sentimento pessoal, que independentemente da sua vontade, lhe dita a escolha do par. Ora, como por tradição chinesa, o amor é sentimento ausente dos casamentos, traçados a pensar na conveniência de interesses das famílias e até das comunidades, as meninas solteiras acabavam, algumas vezes por se suicidar para fugir ao estigma da desobediência (Alves, 2002: 1018- 1019).

As viúvas-noivas são mulheres cujo noivo faleceu e permanecem na casa dos sogros pelo resto dos seus dias, enlaçadas ao noivo morto. Uma morte em vida. As viúvas suicidas são mulheres que na ausência do homem, o marido-morto, perdem seu lugar cultural de esposa-mulher, cabendo-lhes apenas a morte.

As solteiras que se recusam ao casamento de conveniência, uma transgressão, como única forma de escapar aos limites impostos à vida feminina, buscam o suicídio.

As mulheres da rua:

Também, nas mulheres da rua, encontramos o evento do suicídio reservado a elas.

Entre as mulheres de rua são figuras típicas as concubinas. Estas são trazidas, tantas vezes, contra a vontade expressa da esposa, para o mundo da casa. Normalmente são belas ou até fatais, ou, pelo menos, assim as consideram os maridos embeiçados. O suicídio também não era estranho entre jovens reservadas a concubinas que almejavam um futuro mais alto, ou cuja pureza de sentimentos em relação aos entes amados não lhes permitia 
aceitar como natural a situação de segundo plano a que estavam reservadas [...]. Entre as mulheres da rua, encontram-se as abandonadas. Estas, deixadas pelos maridos ou pela sorte, ficam, habitualmente, com os filhos, à mercê de uma sociedade pouco dada a dádivas, por muito acostumada à pobreza. (Alves, 2002: 1020).

Diante das tensões entre feminino-masculino, geralmente desencadeadas pela ausência do masculino (seja pela morte, abandono ou fuga), o recurso possível para a feminino é um desfecho pelo suicídio. O lugar do feminino na cultura chinesa nos parece sempre alicerçado ao homem. Desta forma, quando o masculino se ausenta, um possível esvaziamento do lugar simbólico da mulher entra em movimento. E, por conseguinte, este esvaziamento pode dar impulso a uma morte simbólica, que encerra por arrastar o próprio corpo.

Retomamos nossa questão anterior, da mulher como adorno: $\mathrm{O}$ que significa para alguém, no caso a mulher chinesa, ser ornamento? Que consequências tem para alguém existir para ornar o outro? Talvez, uma das consequências seja que, quando o outro/masculino desaparece, seu lugar simbólico/feminino perde a permanência.

\section{O feminino na sociedade contemporânea na China}

Na atualidade, a condição sociocultural da mulher na China sugere que a herança dos tipos femininos do passado deixou profundas marcas. Através dos relatos de Xinran (2007) pudemos observar situações de impacto nas descrições sobre o cotidiano feminino. Esta jornalista, entre 1989 e 1997, entrevistou mulheres de diferentes localidades, condições sociais e idades na China. Os relatos de violência moral ou física em relação ao feminino eram inúmeros ao longo das entrevistas, bem como os eventos suicidas das vítimas ou de outras mulheres citadas nos casos descritos. Elegemos três fragmentos dentre muitos, sendo que estes fazem parte de um contexto homogêneo, no qual se exibe o lugar do feminino na China.

Carta enviada por Xiau Yu sobre seu namoro e a desonra dos pais.

Por que você nunca leu minha carta? Não entendeu que eu tinha que decidir entre a vida e a morte? Eu o amo, mas nunca fiz nada de errado. Ele nunca tocou meu corpo, mas uma vizinha o viu me beijar na testa e disse para todo mundo que eu era uma mulher má. Meus pais estão muito envergonhados. Amo muito meus pais. Desde que eu era pequena tenho a esperança que eles se orgulhem de mim, que se sintam felizes por ter uma filha bonita e inteligente e não inferiores porque não tiveram um filho [...]. Não há motivo para continuar vivendo. Adeus Xinran. Eu amo e odeio você. (Xinran, 2007: 45) 
Xiao Ying, jovem de dezesseis anos e vítima de estupro coletivo por homens do exército chinês que estavam na província para auxiliar os sobreviventes após um terremoto de dimensões catastróficas.

Olhamos um para o outro, sem falar, e choramos: nossa filha tinha sido brutalizada e ficado louca. [...]. Nós fizemos isso, mas sabíamos que ela continuaria sentindo terror, mesmo que se recuperasse. Dois anos e meio depois, bem quando a memória dela estava voltando ao normal, no dia em que pretendíamos leva-la para casa para começar uma vida nova, ela se enforcou no quarto do hospital. (Xinran, 2007: 94)

As mulheres da colina dos gritos são aldeãs que trabalham em atividades rudimentares e pesadas; numa forte estratificação por gênero, elas são compartilhadas pelos homens da aldeia como os equipamentos agrícolas.

Devido ao grande número de gravidez destas mulheres, todas têm o útero caído para fora do corpo e, assim, precisam caminhar com as pernas semiabertas. As crianças do sexo feminino, quando nascem, são trocadas por suprimentos agrícolas entre as famílias. Data destes eventos: 1995.

Na colina dos gritos não se opõe resistência ao curso da natureza, e planejamento familiar é conceito desconhecido. As mulheres são tratadas como máquinas reprodutoras e produzem um filho por ano, ou até dois filhos a cada três anos. Não há garantia de que as crianças sobrevivam. Pelo que me consta, a única maneira de conter a expansão constante das famílias é a mortalidade infantil ou o aborto causado por exaustão. [...] mesmo as mulheres em final da gestação tinham de continuar trabalhando e eram usadas pelos maridos, cujo raciocínio era de que "só as crianças que resistem a ser esmagadas são fortes o suficiente". Fiquei pasmada com isso, principalmente com a ideia de esposas compartilhadas serem usadas por vários homens durante a gravidez. (Xinran, 2007: 246-247)

A condição feminina revelada nestas entrevistas mostra que, na China moderna, as mulheres permanecem presas às tradições, assim como às relações sociais. Destacou-se o fato de que estas entrevistas não estavam direcionadas para revelar aspectos referentes ao suicídio, porém, a maioria das mulheres entrevistadas relatam episódios de suicídio em suas vidas. Apesar de ser impossível revelar toda a densidade destas entrevistas neste ensaio, estes fragmentos esclarecem a condição feminina na atualidade e a relaciona ao suicídio feminino.

Finalmente, lembramos que no pano de fundo de nossas elaborações, as referências da literatura chinesa foram significativas para compor este ensaio nos aspectos do feminino. Os contos de Deolinda da Conceição, escritora chinesa de 
Macau, em $A$ Cabaia ${ }^{4}$, revelaram aspectos importantes sobre a permanência do suicídio entre as mulheres na China, seja nas figuras do passado, seja na atualidade. Nos contos, a escritora apresenta episódios de suicídios femininos típicos na cultura chinesa (a viúva que se suicida após a morte do marido, a moça prometida num casamento arranjado, entre outras). As releituras destes contos demonstram o caráter de feminismo sutil na obra de Deolinda (Machado, 2014), de forma subliminar o suicídio feminino é redimensionado: saída, submissão ou rebeldia?

Por outro lado, num conto como "O Refúgio da Saudade", o que no Ocidente se toma pela submissão tradicional da mulher chinesa à figura masculina conhece um exemplar acto de resistência: uma rapariga, apaixonada por um arquitecto europeu, aceita deste uma proposta de casamento, ao mesmo tempo que ao pai promete cumprir os deveres de filha afastando-se do estrangeiro; a jovem, fiel ao seu coração mas também respeitosa do pai e ciosa das suas obrigações para com a família, decide-se pelo suicídio não como mera resignação à sua condição de mulher numa sociedade tradicional e sim como forma possível de resistência, já que o destino que lhe coubera ao menos não lhe iria impedir a afirmação da sua vontade. Isso está bastante claro na ironia amarga do bilhete de adeus que a rapariga deixa sobre a mesa, com os seguintes dizeres: "Cumpri a minha promessa" (Conceição $\mathrm{s} / \mathrm{d}, 114)$. Com a promessa feita pela jovem ao pai sendo cumprida com o suicídio (a personagem legitima, na aparência, o papel

\section{Quem é sombra? Quem é objeto?}

Relembrando nosso ponto instigante e inicial: Na China, também, as noivas abandonadas se suicidam com seus vestidos vermelhos de casamento. Elas são o pior tipo de fantasma que existe para um homem, pois perseguem o noivo para toda vida!

Por que mulheres suicidas se transformam no pior tipo de fantasma para um homem na cultura chinesa? Apesar do lugar esvaziado de sentido da mulher na China, pelos próprios princípios da filosofia chinesa, masculino-feminino são um amálgama, uma unidade composta de elementos diferentes e opostos, porém, inseparáveis e complementares. Vejamos a definição de Yin (feminino) e Yang (masculino):

4 Cabaia é a indumentária tradicional chinesa da mulher. 
Yin e Yang são conceitos do taoismo que expõem a dualidade de tudo que existe no universo. Descrevem as duas forças fundamentais opostas e complementares que se encontram em todas as coisas: o yin é o princípio feminino, noite, Lua que precisa de fogo para ilumina e aquecer na escuridão fria noturna, a passividade, absorção. O yang é o princípio masculino, Sol que precisa de Água (refrescar o calor insuportável), dia, a luz e atividade. Segundo essa ideia, cada ser, objeto ou pensamento possui um complemento do qual depende para a sua existência. Esse complemento existe dentro de si. Assim, se deduz que nada existe no estado puro: nem na atividade absoluta, nem na passividade absoluta, mas sim em transformação contínua. (wikipedia, acessaso em 26/o6/16)

Desta forma, temos que o masculino precisa do elemento feminino Yin-águanoite para aplacar Yang-fogo-sol. A existência do par de opostos masculino-feminino em cada ser implica a essência do outro.

Na cena das noivas suicidas chinesas podemos prever a existência de Yang (masculino) ameaçada na medida em que este sujeito masculino estava em dualidade com Yin (feminino), que se precipita para a morte. Nesta perspectiva o noivo é arrastado junto com o elemento feminino, personificado na noiva suicida, devido a desintegração de Yin-Yang. E, assim, podemos supor que o elemento feminino se torna uma sombra-fantasma a perseguir o masculino em vida. Aquela que foi uma sombra do masculino em vida, sem sentido específico, apodera-se de resistência na própria morte e torna-se um fantasma com sentido definido.

Se a mulher é o espelho do homem, onde este pode projetar todo o seu ser, ao subtrair daquele o reflexo, a noiva suicida transforma-o em sombra, tal qual ela - um fantasma, imaterial, pois desprovido de reflexo, privado do autoconhecimento, da afirmação do masculino em oposição ao feminino. Em termos ocidentais e numa perspectiva antropológica, podemos traduzir esta interação entre femininomasculino, dimensão relacional de gênero. Pois, tal interação define ambos num registro simbólico.

Na perspectiva feminista, fundada na experiência compartilhada, há uma identificação entre mim e o outro. A experiência torna-se o instrumento de um conhecimento que não pode ser apropriado pelo outro. [...] O problema é, então, o de estabelecer os termos da comunicação possível, já que se pretende a relação com o outro. (Sarti, 2004:47). 


\section{As Mulheres e o Suicídio no Brasil}

A situação sociocultural da mulher no Brasil é aparentemente menos severa, se comparada às situações descritas anteriormente. Entretanto, sabe-se através de estudos sobre o feminino no Brasil, que o lugar da mulher possui suas enormes vicissitudes. Sobre o suicídio feminino no Brasil, temos os seguintes dados epidemiológicos, suicídios consumados:

Segundo dados da OMS, as taxas específicas de mortalidade por suicídio no Brasil, em 2008, eram de 7,7 óbitos/10o mil homens para o sexo masculino e 2,o óbitos/100 mil mulheres para o sexo feminino. [...] (Brasil, 2011:204).

Por outra via, as tentativas de suicídio entre mulheres no Brasil é expressivamente maior se comparada aos homens, ou seja, acompanha a tendência internacional.

\footnotetext{
Apesar do número de suicídios consumados ser mais significativo entre os homens, o número de tentativas é superior entre as mulheres, além de ser entre elas a maior proporção de aumentos no número de casos - um aumento de cerca de $16,4 \%$ para os homens e $24,7 \%$ para as mulheres no período de 1994 a 2004 (Brasil, 2011: 204)
}

As conclusões geradas a partir destes dados quantitativos é que as mulheres não desejam se matar com a mesma frequência e intensidade, se comparadas aos homens, mas em contrapartida tentam o suicídio mais vezes. Algumas explicações frequentes são: desejo de chamar a atenção para si, traços histéricos, variações hormonais, volatilidade de conduta, impulsividade, emotividade excessiva, falta de racionalidade, entre outros.

Desejamos lançar nossa discussão a partir de outra vertente, ou seja, abordar como a tentativa de suicídio feminina é desqualificada nas suas possíveis significações e, geralmente, retratada como ato de fraqueza. O discurso médico sobre o suicídio foi analisado de forma oportuna por Lopes (2007) para nosso propósito. O autor aborda os discursos médicos no Brasil e na França durante o século XIX e a consequente construção das diferenças entre sexos e sua relação com o suicídio. O autor atinge dois importantes motes do discurso médico referentes ao suicídio feminino. Em primeiro lugar, a construção de um modelo-identidade fixo e determinado biologicamente em relação ao feminino-masculino. Em segundo lugar, uma articulação rígida entre este suposto par de opostos masculino-feminino com o evento do suicídio.

Lopes (2007) observa o problema de uma perspectiva distinta e, assim, faz uma inversão sobre a própria questão para compreender o pensamento científico sobre o 
suicídio. Ou seja, ele não indaga sobre os motivos porque as mulheres apresentam maiores taxas de tentativas de suicídio e menores taxas de óbitos por suicídio. Mas, por outra via, questiona as incoerências entre a associação do evento suicida e o perfil de personalidade traçado para o feminino e masculino. Vejamos as palavras do autor:

Se o homem é, de acordo com a discursividade médica, superior à mulher, se é mais acostumado a pensar, raciocinar e discernir, se é mais forte, mais apto à vida social e muito mais resistente às vicissitudes da vida, poderíamos entender o porquê de ele se suicidar menos. Se as mulheres são fracas, débeis, limitadas, sentimentais, emotivas e frívolas, seria até mesmo "óbvio" e "natural" elas se suicidarem em maior número. Contudo, os dados empíricos revelam exatamente o oposto. Elas se suicidam menos do que os homens! Se os médicos têm razão, se o homem é superior à mulher, por que elas se suicidam muito menos do que eles? Quais as respostas desses estudiosos? Como explicar esse paradoxo? As respostas remetem, uma vez mais, à inferioridade das mulheres. (Lopes, 2007:251).

A perspectiva do autor traz uma reviravolta no sentido das indagações sobre o evento suicida e a questão de gênero. E, desta forma, mostra a fragilidade do discurso médico sobre o suicídio que perdura até os dias de hoje. Entretanto, o 267 discurso médico, totalizante como é, sempre guarda suas respostas por mais ilógicas que possam parecer:

[...] uma explicação satisfatória é que as mulheres geralmente não desejam o suicídio no sentido de destruição, aniquilamento, pois o que elas querem é "simplesmente" fugir, esquecer, escapar de sua vida presente, dormir, dormir muito e por muito tempo. Dessa maneira, seria possível compreender as razões de elas não se disporem de meios considerados "radicais". Esses meios radicais e violentos seriam características de suicídio masculino. Assim, estabelece-se que as mulheres não teriam força necessária para o suicídio. Fracas, tornam-se loucas, não suicidas. Os homens, fortes e mais decididos, tornam-se suicidas, utilizando os meios considerados mais violentos. (Lopes, 2007: 255).

Portanto, temos a conclusão do discurso médico que as mulheres se suicidam menos porque são menos racionais e loucas. Estranha conclusão, porém, perpetrada no discurso médico moderno. Apenas como confirmação citamos o discurso médico atual:

Entre os fatores sócio-demográficos e clínicos, associados à ideação e as tentativas de suicídio, estudos internacionais destacam, de modo geral: o gênero feminino [...]. (Botega, 2009: 2636). 
O discurso médico alinha-se sob a mesma ótica da tradição chinesa, colocando-a como frágil e incapaz de uma ação.

\section{Reflexões Finais}

Este ensaio sobre noivas suicidas disparou, a partir das cenas descritas, acreditando que as mulheres orientais e ocidentais, embora separadas pela diferença de cultura, mantinham algo em comum: a condição de noivas abandonadas. Nas mulheres chinesas encontramos através da literatura, nos mitos, nos contos românticos e nas histórias jornalísticas, a intrínseca relação entre suicídio e a condição sociocultural feminina. Nas mulheres ocidentais, especificamente as brasileiras, encontramos através do discurso médico e seus paradoxos, outra relação de domínio que aniquila o possível caráter simbólico do evento suicida feminino. $\mathrm{O}$ suicídio feminino e suas significações se transformaram minino çral em fraqueza e loucura.

Os scripts das cenas de noivas suicidas estavam permeados pela justaposição dos elementos masculino-feminino e procurávamos um esclarecimento, mesmo que parcial, sobre o lugar simbólico da mulher nas suas culturas e as possíveis relações deste com o suicídio.

Na China, nos parece que encontramos uma ausência de lugar para a mulher, lugar nulo, de objeto aderido à figura masculina. Em uma palavra: um adorno. No Brasil, através das peripécias do discurso médico, o homem que pratica o suicídio efetivo ocupa o lugar da racionalidade e do discernimento. E, à mulher que faz suas tentativas de suicídio, cabe o lugar simbólico da loucura e da fraqueza.

Na abordagem antropológica, há uma longa tradição sobre a necessidade de se aproximar dos grupos diferentes que estudamos, ou seja, aqueles estranhos à cultura do próprio pesquisador. Neste caso as mulheres chinesas.

Mas, a antropologia também reconhece o estranho naqueles com quem convivemos cotidianamente e não nos damos conta de suas singularidades. Para estas situações a antropologia propõe que façamos um estranhamento do próximo para que possamos descobrir suas particularidades e, desta forma, não naturalizar os eventos que estudamos. Assim, se deu conosco e o discurso médico sobre o suicídio feminino no Brasil.

Ou seja, no discurso científico ocidental, as tentativas de suicídio (em sua maioria dentre o sexo feminino) estão tão fixamente articuladas a conceitos de fraqueza e falta de racionalidade, que não se podia observar a contradição do discurso médico proposta por Lopes (2007):

Se as mulheres são fracas, débeis, limitadas, sentimentais, emotivas e frívolas, seria até mesmo "óbvio" e "natural" elas se suicidarem em maior número... Se os médicos têm razão, se o homem é superior à mulher, por que elas se suicidam muito menos do que eles? (Lopes, 2007: 251). 
Elas, as mulheres-noivas que se suicidam na passarela, eram tão próximas a nós que não escutávamos o discurso construído sobre elas. Portanto, se tornou mais fácil encontrar o estranho no suicídio das mulheres chinesas tão distantes. Naquilo que se espelha nos eventos suicidas femininos destas duas culturas, talvez, a principal diferença de domínio do masculino sobre o feminino, seja apenas a sofisticação do discurso.

\section{Referências Bibliográficas}

ALVES, Ana. (2002) A mulher chinesa na sociedade contemporânea. Tese (Mestrado em Filosofia). Programa de Pós-Graduação em Filosofia, Faculdade de Filosofia, Macau, impressa.

BOTEGA, Neury. et al. (2009). "Prevalências de ideação, plano e tentativa de suicídio: um inquérito de base populacional em Campinas/São Paulo". Cadernos de Saúde Pública, n.25,12: p. 2632-2638, dez.

BRASIL, Secretaria de Vigilância em Saúde/Ministério da Saúde (2011). Saúde Brasil: uma análise da situação de saúde e a vigilância da saúde da mulher. Mortalidade do adulto no Brasil: taxas de mortalidade segundo o sexo, as causas e as regiões, 2010. Disponível em: http://portalsaude.saude.gov.br/portalsaude. Acesso em: 22 mai. 2017.

JANDT, Fred. (2004) An Introduction to Intercultural Communication: Identities in a Global Community. 4 Edição. London, Sage Publications.

LOPES, Fábio. (2007). "Medicina, educação e gênero: as diferenciações sexuais do suicídio nos discursos médicos do século XIX” Educar, Curitiba, n. 29: p. 241-257, abr.

MACHADO, Everton. (2014) "A mulher oriental em duas escritas da Ásia portuguesa: Deolinda da Conceição (Macau) e Vimala Devi (Goa)” Babilónia: Revista Lusófona de Línguas, Culturas e Tradução. Lisboa, n. 12: p. 33-45, jun.

MARQUETTI, Fernanda. (2013). O Suicídio como espetáculo na metrópole. 1 edição. São Paulo/SP. Editora Fap-Unifesp.

MEDRADO, Benedito. \& LYRA, Jorge. (2008) "Por uma matriz feminista de gênero para os estudos sobre homens e masculinidades”. Revista Estudos Feministas. Florianópolis, n. 16, 3: p. 809-840, set-dez.

MELLO-SANTOS Carolina, \& WANG Yuan-Pang. (2005) "Epidemiology of suicide in Brazil 1980-200o”. Revista Brasileira de Psiquiatria, São Paulo, n. 2, 27: p.131-134. 
MENEGHEL, Stela Nazharet, etal. (2013) “Suicídio de Mulheres: uma Situação Limite?” Athenea Digital, Barcelona, n.13, 2: p. 207-217, jul.

SARTI, Cynthia. (2004). "O feminismo brasileiro desde os anos 1970: revisitando uma trajetória” Estudos Feministas, Florianópolis, n.12, 2: p. 35-50, mai-ago.

XINRAN, Xinran. (2007). As Boas Mulheres da China: vozes ocultas. 4 edição. São Paulo, Cias das Letras.

YING-YEH Chen, et al. (2014). "Suicide in Asia: Opportunities and Challenges". Epidemiolic Reviews. Oxforde, n.34, n.1: p. 129-144

WHO. (2004). Preventing suicide: a global imperative. Global epidemiology of suicide and suicide attempts... WHO. Disponível em: http://www.who.int/mental_health/ suicide-prevention/world_report_2014/en/. Acesso em 25 abr. 2017.

WIKIPÉDIA,(2016).Yin-Yang. Enciclopédia Livre. Disponível em: https://pt.wikipedia. org/wiki/Yin-yang. Acesso em 26 jun. 2016.

Recebido: 05.10.2018

Aceito: 30.10 .2018 